\title{
What is the role of metabolic syndrome and obesity for postoperative atrial fibrillation after coronary bypass grafting?
}

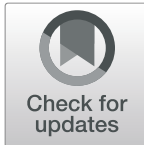

Ünsal Vural ${ }^{*}$ and Ahmet Arif Ağlar@i

\begin{abstract}
Background: Postoperative atrial fibrillation is the most common arrhythmia seen after cardiac surgery. We aimed to determine the effect of obesity and metabolic syndrome on postoperative atrial fibrillation, whether they are independent risk factors, and their effect level. We also analyzed the effect of atrial fibrillation on postoperative complications.

Methods: In our clinic, 756 patients who underwent coronary artery bypass grafting between June 2010-September 2017 were evaluated retrospectively. Preoperatively, demographic characteristics, chronic diseases, body mass index, waist circumference measurements, and ejection fraction values of the cases were determined from file records. Perioperatively, cross-clamp and cardiopulmonary bypass times, intra-aortic balloon use, distal coronary bypass counts were determined. Postoperatively, complications, duration of intensive care unit and hospital stay, and mortality were evaluated. The patients were followed up with continuous 3-lead ECG monitorization on the postoperative first day and 12-lead ECG records once in a day on the remaining days. In the study, the first endpoint was the determination of atrial fibrillation and the second endpoint was the discharge time of the patient.
\end{abstract}

Results: The rate of postoperative atrial fibrillation was $21.3 \%$. Atrial fibrillation was seen in $33 \%$ of metabolic syndrome cases and in 38.5\% of obese cases. Atrial fibrillation was seen in 23, 24 and 17\% of cases using statin, ACE inhibitor and beta blocker, respectively. It was seen in $21 \%$ of smokers and $20 \%$ of the COPD cases. In the study, metabolic syndrome, diabetes mellitus, hypertension, and obesity, between the ages of 56-78 with Metabolic syndrome, were found to affect the development of postoperative atrial fibrillation (2.46), (2.3), (1.6), and (1.65) times, respectively. In cases with postoperative atrial fibrillation, infection and stroke were 1.45 and 8.85 times more frequent, respectively. Patients with metabolic syndrome were found to have 31\% longer hospital stay, and $17 \%$ higher infection rate. In obese patients, hospitalization was 23.5\% longer.

Conclusions: Metabolic syndrome and obesity were found to be two independent risk factors for postoperative atrial fibrillation. If causes and mechanisms of postoperative atrial fibrillation are identified in planned cardiovascular interventions, we believe that cost of hospitalization and morbidity will be reduced.

Keywords: Metabolic syndrome, Obesity, Atrial fibrillation, Coronary bypass grafting, Postoperative evaluations

\footnotetext{
* Correspondence: unsalvural@gmail.com

Dr. Siyami Ersek Kalp ve Damar Cerrahisi Eğitim ve Araştırma Hastanesi

Cardiovascular Surgery Clinic, Tıbbiye Cad. Haydarpasa Uskudar, 34668

Istanbul, Turkey
}

(C) The Author(s). 2019 Open Access This article is distributed under the terms of the Creative Commons Attribution 4.0 International License (http://creativecommons.org/licenses/by/4.0/), which permits unrestricted use, distribution, and reproduction in any medium, provided you give appropriate credit to the original author(s) and the source, provide a link to the Creative Commons license, and indicate if changes were made. The Creative Commons Public Domain Dedication waiver (http://creativecommons.org/publicdomain/zero/1.0/) applies to the data made available in this article, unless otherwise stated. 


\section{Background}

The metabolic syndrome (MS) is known as a syndrome characterized by increased abdominal obesity, increased insulin resistance, decreased high-density lipoprotein (HDL), and elevated Low-density lipoprotein. In the United States, it is reported that its prevalence is more than $27 \%$ over 20 years of age and in women [1]. Kozan et al. reported that in Turkey, metabolic syndrome was seen in $33.9 \%$ of the population over 20 years of age and more frequently in women [2]. These data were obtained when the upper limit of the waist circumference is 102 $\mathrm{cm}$ for men and $88 \mathrm{~cm}$ for women. We believe that today's accepted upper limits of 94 and $80 \mathrm{~cm}$ increase these rates. In MS, increased circulating cytokines secondary to metabolic disorders are thought to stimulate atrial fibrillation (AF). The incidence of $\mathrm{AF}$ is $0.4 \%$ in the general population, 30-40\% after coronary artery bypass grafting (CABG), and 60\% after valve surgery [3]. In the USA, it is known that AF-caused hospital admissions have increased by $66 \%$ over the last 20 years [4]. Postoperative atrial fibrillation (POAF) has been reported to increase hospital admissions in the US by $\sim 30$ days, resulting in an additional cost of $\$ 18,000-19,000$ and a 2 or 3-fold increase in stroke risk [5]. Watanabe et al. demonstrated that metabolic syndrome is an independent risk factor for AF development even in the absence of diabetes and hypertension (HT), and is strongly associated with stroke, myocardial infarction (MI), and allcause mortality [6].

In this study, we aimed to evaluate whether obesity and metabolic syndrome are independent risk factors among the risk factors affecting POAF in the light of literature. We also analyzed the effect of factors that stimulated POAF formation on postoperative complications and length of hospital stay.

\section{Methods}

This study was performed at Dr. Siyami Ersek Thoracic and Cardiovascular Surgery Center Istanbul, Turkey. The study protocol was approved by the Health Sciences University Siyami Ersek Cardiovascular Surgery Hospital Ethics Committee decision dated 16/06/2015 and numbered (Number No: 28001928-501.07.01) and the patients were informed in writing. Informed consent was waived by Institutional Review Board owing to the study's retrospective nature.

\section{Study population}

In our clinic, 756 patients who underwent isolated CABG between June 2010 and September 2017 were evaluated retrospectively. Patients with preoperative AF treatment (1), additional cardiac interventions (2), hyperthyroidism (3), moderate-to-severe liver (4) and renal (5) failure, malignancy (6) and those with no available record of body mass index (BMI) and waist circumference (WC) measurements were excluded. Table 1 shows the demographic characteristics of the cases [age, gender, drugs used (statin, beta blocker, Angiotensin converting enzyme inhibitors (ACE)), smoking, BMI, history of diabetes mellitus (DM), HT, chronic obstructive pulmonary disease (COPD) and post-myocardial infarction, measurements of triglyceride (TG), HDL, waist circumference and left ventricular ejection fraction (LVEF)]. Perioperatively, total and partial cardiopulmonary bypass $(\mathrm{CPB})$ times, Intraaortic balloon pomp use, and the number of bypasses were determined. Postoperatively, infection, stroke, hemorrhage, duration of intensive care unit (ICU) and hospitalization and mortality were evaluated (Fig. 1). POAF formation of MS and obesity cases were compared to each other and to non-AF cases (Table 1).

For the diagnosis of MS, diagnostic criteria proposed by MS Working Group of The Society of Endocrinology and Metabolism of Turkey (2005) were taken as basis [7]. Accordingly, to establish the MS diagnosis, in addition to presence of at least one of the such parameters as DM, impaired glucose tolerance or insulin resistance, having at least two of following parameters of (I) HT (systolic $>130 \mathrm{mmHg}$, diastolic $>85 \mathrm{mmHg}$ or being under antihypertensive drug therapy), (II) dyslipidemia (TG $>150 \mathrm{mg} / \mathrm{dl}$ or $\mathrm{HDL} \leq 40 \mathrm{mg} / \mathrm{dl}$ for $\mathrm{male} / 50 \mathrm{mg} / \mathrm{dl}$ for female), (III) abdominal obesity (BMI $>30 \mathrm{~kg} / \mathrm{m}^{2}$ or WC $>94 \mathrm{~cm}$ for male and $>80 \mathrm{~cm}$ for female) was required. The waist circumference was measured through the middle of the distance between the arcus costarium and the spina iliaca anterior superior. BMI was used for the detection of obesity.

\section{Follow up in hospital}

The cases were followed by continuous Electrocardiography (ECG) monitoring for the first $24 \mathrm{~h}$ postoperatively while daily 12-lead ECG record was used for rhythm follow-up on other days. Patients with AF rhythm were monitored until the sinus rhythm was restored. In addition, ECG recording was taken in case of arrhythmia. Amiodarone hydrochloride loading and maintenance doses [8 ampoules (1200 mg) in 500 cc \%5 Dextrose solution] were administered to patients who developed AF rhythm. Loading dose of $5-10 \mathrm{mg} / \mathrm{kg}$ was administered intravenously within the first $30 \mathrm{~min}$. Maintenance dose was administered as $36-60$ $\mathrm{mg} / \mathrm{h}$ (900-1500 mg/day). Oral amiodarone (200 mg; $2 \times 1)$ started after $24 \mathrm{~h}$. Low-molecular-weight heparin (enoxaparin sodium $75 \mathrm{IU} / \mathrm{kg}$ ) was given to patients with AF. Mechanical cardioversion was applied to the cases resistant to medical cardioversion within first $24 \mathrm{~h}$. Postoperatively, all cases had continued to use the beta blocker, statin and ACE inhibitor used before the operation. In the study, the first endpoint was the detection of atrial fibrillation and the second endpoint was the discharge time. 
Table 1 Statistical analysis of cases according to POAF and Metabolic Syndrome status $\left(\mathrm{p}^{(\mathrm{a})}=\right.$ Independent sample t-test, $\mathrm{p}^{(\mathrm{b})}=$ Pearson chi-square test, $p<0.05$ was considered significant.) $C P B=$ Cardiopulmonary bypass, IABP = Intraaortic balloon pump, $\mathrm{MI}=$ Myocardial infarction, $\mathrm{TG}=$ Triglyceride, $(+)=$ available, $(-)=$ unavailable)

\begin{tabular}{|c|c|c|c|c|c|c|c|c|c|c|c|c|c|c|}
\hline & & \multicolumn{13}{|c|}{ Postoperative Atrial Fibrillation } \\
\hline & & \multicolumn{6}{|c|}{ Unavailable } & \multicolumn{6}{|c|}{ Available } & \multirow{4}{*}{$\begin{array}{l}\text { Total } \\
p^{(b)}\end{array}$} \\
\hline & & \multicolumn{6}{|c|}{ Metabolic Syndrome } & \multicolumn{6}{|c|}{ Metabolic Syndrome } & \\
\hline & & \multicolumn{2}{|c|}{ Unavailable } & \multicolumn{2}{|c|}{ Available } & \multirow[t]{2}{*}{ Total } & \multirow[t]{2}{*}{$P^{(b)}$} & \multicolumn{2}{|c|}{ Unavailable } & \multicolumn{2}{|c|}{ Available } & \multirow[t]{2}{*}{ Total } & \multirow[t]{2}{*}{$p^{(b)}$} & \\
\hline & & $n$ & $\%$ & $n$ & $\%$ & & & $n$ & $\%$ & $n$ & $\%$ & & & \\
\hline \multirow[t]{2}{*}{ Gender } & Female & 132 & 74,6 & 45 & 25,4 & 177 & 0,92 & 30 & 57,7 & 22 & 42,3 & 52 & 0,52 & 0,53 \\
\hline & Male & 310 & 74,2 & 108 & 25,8 & 418 & & 57 & 52,3 & 52 & 47,7 & 109 & & \\
\hline \multirow[t]{3}{*}{ Age } & $18-35$ & 21 & 75,0 & 7 & 25,0 & 28 & 0,01 & 3 & 50,0 & 3 & 50,0 & 6 & 0,38 & 0,01 \\
\hline & $36-55$ & 185 & 76,4 & 57 & 23,6 & 242 & & 21 & 45,7 & 25 & 54,3 & 46 & & \\
\hline & $56-78$ & 236 & 72,6 & 89 & 27,4 & 325 & & 63 & 57,8 & 46 & 42,2 & 109 & & \\
\hline \multirow[t]{3}{*}{ BMl } & $<25$ & 249 & 100 & 0 & 0,0 & 249 & 0,01 & 35 & 89,7 & 4 & 10,3 & 39 & 0,01 & 0,01 \\
\hline & $25-30$ & 173 & 83,6 & 34 & 16,4 & 207 & & 42 & 70,0 & 18 & 30,0 & 60 & & \\
\hline & $>30$ & 20 & 14,4 & 119 & 85,6 & 139 & & 10 & 16,1 & 52 & 83,9 & 62 & & \\
\hline \multirow[t]{2}{*}{ ACE Use } & $(-)$ & 362 & 95,5 & 17 & 4,5 & 379 & 0,01 & 72 & 75,8 & 23 & 24,2 & 95 & 0,01 & 0,27 \\
\hline & $(+)$ & 80 & 37,0 & 136 & 63,0 & 216 & & 15 & 22,7 & 51 & 77,3 & 66 & & \\
\hline \multirow[t]{2}{*}{ Statin Use } & $(-)$ & 421 & 78,1 & 118 & 21,9 & 539 & 0,01 & 83 & 57,2 & 62 & 42,8 & 145 & 0,01 & 0,84 \\
\hline & $(+)$ & 21 & 37,5 & 35 & 62,5 & 56 & & 4 & 25,0 & 12 & 75,0 & 16 & & \\
\hline \multirow[t]{2}{*}{ Beta-Blocker Use } & $(-)$ & 302 & 75,3 & 99 & 24,7 & 401 & 0,41 & 63 & 52,1 & 58 & 47,9 & 121 & 0,38 & 0,05 \\
\hline & $(+)$ & 140 & 72,2 & 54 & 27,8 & 194 & & 24 & 60,0 & 16 & 40,0 & 40 & & \\
\hline \multirow[t]{2}{*}{ Cigaret Use } & $(-)$ & 296 & 73,6 & 106 & 26,4 & 402 & 0,60 & 61 & 55,0 & 50 & 45,0 & 111 & 0,73 & 0,74 \\
\hline & $(+)$ & 146 & 75,6 & 47 & 24,4 & 193 & & 26 & 52,0 & 24 & 48,0 & 50 & & \\
\hline \multirow[t]{2}{*}{ Hypertension } & $(-)$ & 406 & 95,8 & 18 & 4,2 & 424 & 0,01 & 83 & 84,7 & 15 & 15,3 & 98 & 0,01 & 0,01 \\
\hline & $(+)$ & 36 & 21,1 & 135 & 78,9 & 171 & & 4 & 6,3 & 59 & 93,7 & 63 & & \\
\hline Diabetes Mellitus & $(-)$ & 409 & 99,8 & 1 & 0,2 & 410 & 0,01 & 79 & 100,0 & 0 & 0,0 & 79 & 0,01 & 0,01 \\
\hline & $(+)$ & 33 & 17,8 & 152 & 82,2 & 185 & & 8 & 9,8 & 74 & 90,2 & 82 & & \\
\hline COPD & $(-)$ & 316 & 74,5 & 108 & 25,5 & 424 & 0,83 & 63 & 53,4 & 55 & 46,6 & 118 & 0,79 & 0,61 \\
\hline & $(+)$ & 126 & 73,7 & 45 & 26,3 & 171 & & 24 & 55,8 & 19 & 44,2 & 43 & & \\
\hline MI (passed) & $(-)$ & 390 & 74,7 & 132 & 25,3 & 522 & 0,52 & 73 & 52,9 & 65 & 47,1 & 138 & 0,48 & 0,49 \\
\hline & $(+)$ & 52 & 71,2 & 21 & 28,8 & 73 & & 14 & 60,9 & 9 & 39,1 & 23 & & \\
\hline IABP & $(-)$ & 415 & 73,7 & 148 & 26,3 & 563 & 0,18 & 81 & 54,0 & 69 & 46,0 & 150 & 0,97 & 0,48 \\
\hline & $(+)$ & 27 & 84,4 & 5 & 15,6 & 32 & & 6 & 54,5 & 5 & 45,5 & 11 & & \\
\hline & & Ort. & SS & Ort. & ss & Ort. & $p^{(a)}$ & Ort. & ss & Ort & SS & Ort & $p^{(a)}$ & Total $p^{(a)}$ \\
\hline TG (mg/dl) & & 170,0 & 33,2 & 200,4 & 56,3 & 185,2 & 0,01 & 169,2 & 34,3 & 187,6 & 48,4 & 178,4 & 0,01 & 0,96 \\
\hline $\mathrm{HDL}(\mathrm{mg} / \mathrm{dl})$ & & 38,9 & 7,5 & 37,0 & 6,5 & 38,0 & 0,01 & 39,1 & 6,9 & 38,2 & 7,2 & 38,7 & 0,44 & 0,67 \\
\hline Total CPB (/min) & & 86,2 & 6,5 & 86,4 & 7,2 & 86,3 & 0,82 & 84,7 & 6,1 & 87,2 & 7,7 & 86,0 & 0,02 & 0,53 \\
\hline $\mathrm{CCT}(/ \mathrm{min})$ & & 56,2 & 6,5 & 56,4 & 7,2 & 56,3 & 0,82 & 54,7 & 6,1 & 57,2 & 7,7 & 56,0 & 0,02 & 0,54 \\
\hline LVEF (\%) & & 51,1 & 7,9 & 49,7 & 9,0 & 50,4 & 0,06 & 49,7 & 9,4 & 48,9 & 9,2 & 49,3 & 0,57 & 0,08 \\
\hline Hospitalization (/d & & 7,8 & 1,6 & 8,3 & 1,9 & 8,1 & 0,01 & 8,7 & 1,5 & 9,1 & 2,1 & 8,9 & 0,11 & 0,01 \\
\hline CABG & & 2,9 & 0,4 & 2,9 & 0,4 & 2,9 & 0,85 & 2,8 & 0,4 & 2,9 & 0,4 & 2,8 & 0,18 & 0,39 \\
\hline Waist circumferen & (cm) & 76,9 & 11,8 & 95,3 & 10,6 & 86,1 & 0,01 & 84,5 & 11,6 & 96,8 & 10,4 & 90,6 & 0,01 & 0,01 \\
\hline
\end{tabular}




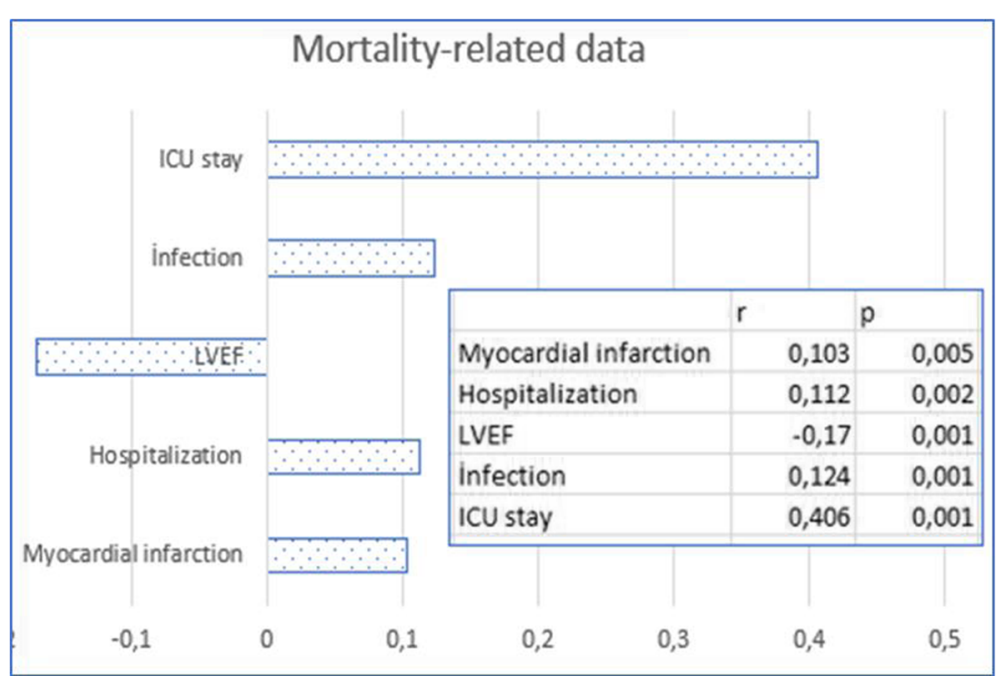

Fig. 1 Significance status of the mortality associated factors and direction of the relationship

\section{Statistical analysis}

Continuous variables were expressed as a mean and standard deviation, while intermittent variables were expressed as number and percentage. Shapiro-Wilk test was used to determine whether the data were normally distributed. In the independent, continuous and normally distributed variables, Student's t-test was used for binary comparisons whereas ANOVA F-test was used for triple or more comparisons. The Tukey posthoc test was used to analyze the difference between the three groups. Mann Whitney U-test was used for binary comparison of non-normally distributed variables while the Kruskal Wallis H-test was used for triple or more comparisons. Chi-square, Fisher exact and Yates continuitycorrection tests were used for comparison and risk analysis of the nominal data of the two groups. The relationship between the groups was analyzed by the Pearson correlation test. Logistic regression was used to determine the effect of dependent and independent factors of POAF. The data were analyzed with the SPSS 17.0 statistical program for Windows. The number of samples was determined such that $\alpha \leq 0.05$ and $\beta \leq 0.20$ in the study. Values of $p \leq 0.05$ were considered significant.

\section{Result}

Of the 756 cases (Mean age $=58.7 \pm 12.8$; male $=527)$ included in the study, $21.3 \%(n=161)$ had POAF. In $88 \%$ of cases with POAF $(n=142)$, AF rhythm occurred within $1-5$ days, postoperatively. In $98 \%(n=158)$ of cases with POAF, sinus rhythm was restored within 1-3 days.

AF rhythm developed in $23 \%(n=52)$ of female cases and in $21 \%(n=109)$ of males. Distribution by sex was not significant $(p=0.532)$. The difference was significant in obese cases $\left(\mathrm{BMI} \geq 30 \mathrm{~kg} / \mathrm{m}^{2} ; p=0.001\right.$; Table 1$)$. It was found that $33 \%(n=74 ; p=0.001)$ of cases with MS,
$23 \%(n=16 ; p=0.840)$ of statin users, $24 \%(n=66 ; p=$ $0.275)$ of ACE inhibitor users, $17 \%(n=40 ; P=0.059)$ of beta-blocker users, 21\% ( $n=50 ; P=0.739)$ of smokers and $20 \%(n=43)$ of cases with COPD developed POAF (Table 1). The development of POAF was found to increase the length of hospitalization by $20.7 \%(p=0.001)$. POAF development was associated with BMI by $16.9 \%$ $(P=0.001)$, with $\mathrm{WC}$ by $24.7 \%(P=0.001)$, and with age by $7.3 \%$ ( $p=0.044$; Figs. 2 and 3 ; Table 1$)$. The mean of waist circumference was $90.1 \pm 12.6 \mathrm{~cm}$ in the cases with POAF while was $81.6 \pm 14.0 \mathrm{~cm}$ in the other cases. The difference was significant $(p=0.004)$. Incidence of postoperative atrial fibrillation was increased by 2.46 times $(n=74 ; \mathrm{OR}=2.4695 \% \mathrm{CI}=1.7-3.5)$ in cases with $\mathrm{MS}$, by 2.3 times $(n=82 ; \mathrm{OR}=2.3 ; 95 \% \mathrm{CI}=1.61-3.3)$ in cases with DM, and by 1.6 times $(n=63 \mathrm{OR}=1.59$; $95 \%$ $\mathrm{CI}=1.1-2.3)$ in hypertensive cases. The postoperative infection and stroke were found to be 1.45-fold ( $n=16$; $\mathrm{OR}=1.4595 \% \mathrm{CI}=0.794-2.66$; Table 2), and 8.8-fold $(n=23 ; \mathrm{OR}=8.84 \% 95 \mathrm{CI}=4.2-18.5)$ more frequent in MS cases, respectively. There was no relationship between mortality and POAF.

MS was present in $29.5 \%$ of the female cases $(n=67$; $p=0.7661)$. Since MS was frequent in advanced age patients, $31 \%(n=135)$ of the POAF cases were in the $56-78$ age group. POAF occurred in $46 \%$ of cases with MS ( $n=$ $74 ; p=0.001$; Table 2). When cases with MS who developed POAF were evaluated alone, lengths of hospitalization and intensive care unit stay were found to be increased by $18.1 \%$ ( $0.6 /$ day $)$ and by $11 \%$ ( $0.3 /$ day), respectively (Figs. 4, 5 and 6). 43\% of postoperative infections $(n=25 ; p=0.024 ; \mathrm{OR}=1.8695 \% \mathrm{CI}=1.08-3.2)$ and $44 \%$ of strokes $(n=15$; OR $=1.995 \% \mathrm{CI}=0.95-3.8)$ were found to be occurred in cases with MS (Table 2; Fig. 5). Mortality was found to be 1.7 times higher in cases with 


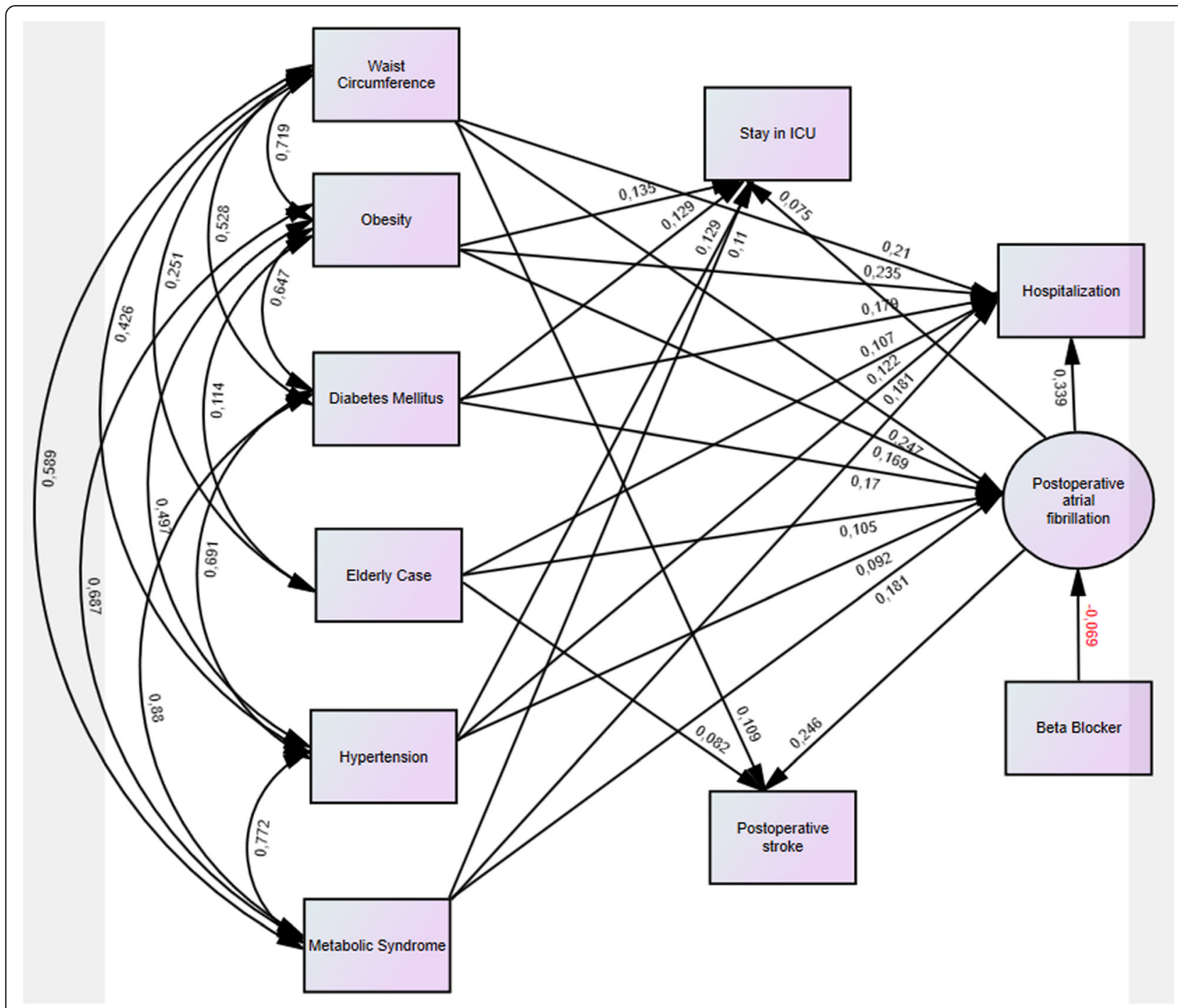

Fig. 2 The demographic characteristics of the patients were positively correlated with each other and with postoperative atrial fibrillation. The picture shows the direction of the interaction and the correlation coefficients r. Similarly, demographic features which were shown in the picture, and atrial fibrillation, were found to be related positively with both intensive care and hospital stay

MS $(n=7 ; p=0.310 ; \quad$ OR $=1.6595 \% \quad \mathrm{CI}=0.62-4.39$; Table 2). However, it was not statistically significant.

Of the 201 patients $(26.6 \%)$ who were obese according to BMI, $30.8 \%$ was found to have POAF $(30.8 \% ; n=62$; $p=0.001)$ and the difference was significant compared to normal cases. $13.4 \%$ of postoperative infections $(n=27$; $p=0.001)$ were seen in this group. There was a significant positive correlation between postoperative infection and BMI $(17 \% ; p=0.001)$. However, there was a low positive correlation with stroke ( $p=0.292$; Figs. 2 and 6). Mortality was higher than the other groups (3.5\%) but the relationship was not significant ( $p=0.386$; Fig. 1$)$. In the obese cases, the hospitalization period was found to be $23.5 \%$ longer. Obesity increased the risk of AF by 1.65 -fold $(n=$ 62 ; $\mathrm{OR}=1.6595 \% \mathrm{CI}=1.4-1.9)$ in the $56-78$ age group.
There was a positive correlation between age and $\mathrm{AF}$ ( $p=0.010$; Fig. 2). In the cases without MS, the rate of AF, which was $25 \%$ in the $18-35$ age group increased to $27.4 \%$ in the $56-78$ age group. However, in cases where metabolic syndrome was added, these rates increased up to $50 \%$ (Table 1). However, the number of cases with both metabolic syndrome and atrial fibrillation was low in the 18-35 age group due to insufficient number of cases with coronary bypass. POAF rates in cases with MS were between 42 and 54\% in the 36-56 and 56-78 age groups where the number of cases were enough. When all cases considered, AF developed in $17.6 \%$ of the cases $(n=6)$ belonging to the $18-35$ age group, in $16 \%$ of the cases $(n=46)$ belonging to the $36-55$ age group, and in $25 \%$ of the cases $(n=109)$ belonging to 


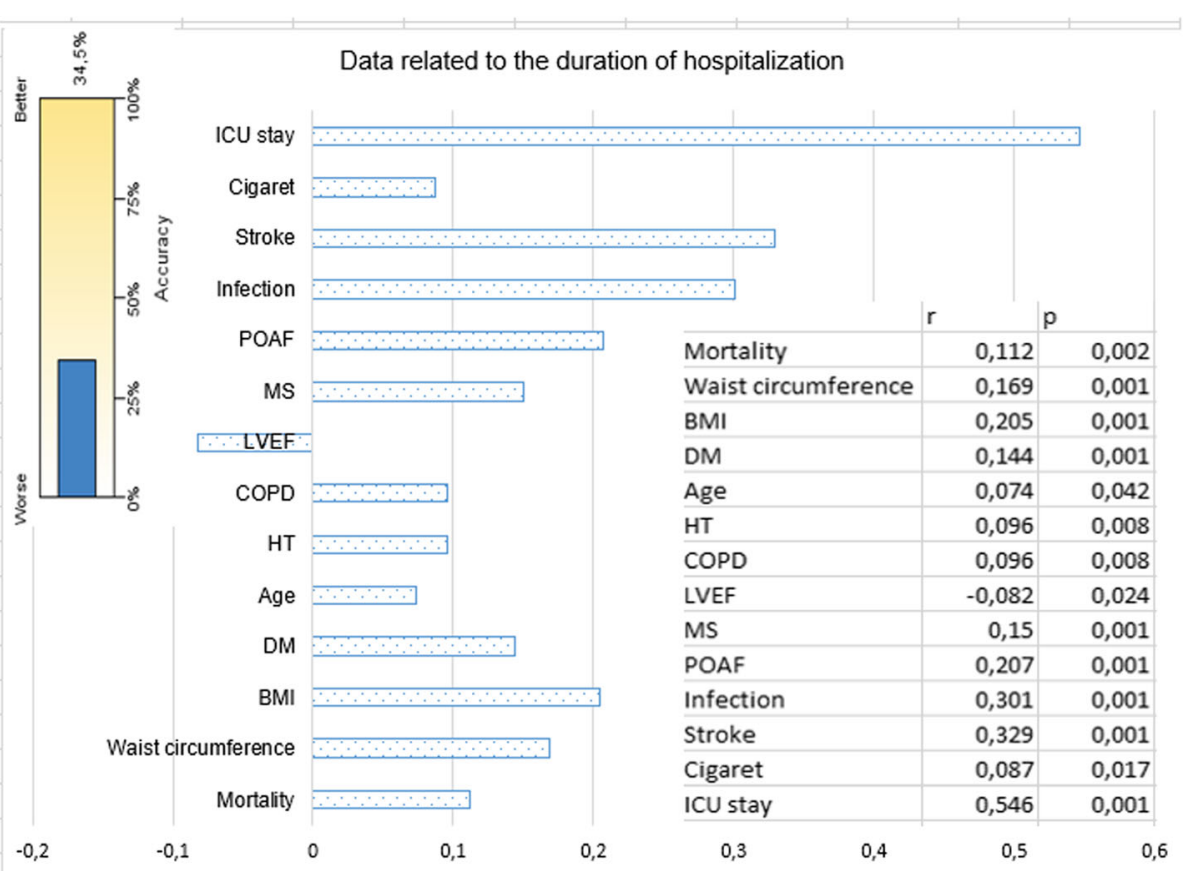

Fig. 3 The parameters that affect the length of hospitalization, $p$-values, $r$-correlation coefficients showing the direction and rate of effect, and significance levels are shown. Data reveals $34.5 \%$ of all factors affecting the length of hospital stay

the $56-80$ age group. $67.7 \%$ of cases with AF were in the 56-78 age group ( $p=0.012$; Table 1$)$. The rate of postoperative infection in the same age group was $9.9 \%(p=$ 0.026). Effect of the age on the length of hospitalization in the POAF developed cases was found to be $10.7 \%$ $(p=0.012)$ and that was statistically significant. There was $6 \%$ relationship between stroke and age but not significant ( $n=26 ; p=0.058$ ). In addition to higher MS incidence in elderly patients, there was also a positive relationship between POAF and age in the cases without MS $(p=0.02 ; r=0.10)$.

When the patients with the metabolic syndrome alone were evaluated in terms of AF occurrence, the increase in AF risk was not significant in the 18-35 age group $(p=0.223)$, was 3.7 times in the $36-55$ age group ( $p=$ 0.001; $\mathrm{OR}=3.8695 \% \mathrm{CI}=2.01-7.41)$, and was 1.9 times in the 56-79 age group ( $p=0.001$; $\mathrm{OR}=1.9695 \% \mathrm{CI}=$ 1.23-3.04; Table 1). Although these results were a discordance with age increase, this was a result of the shadowing of the age by metabolic syndrome. Hypertension was diagnosed in $31 \%(n=234)$ of the cases. In $26.9 \%$ $(n=63 ; p=0.011$; Table 1$)$ of hypertensive cases, POAF developed and the relation was significant. MS was detected in $82.9 \%$ of hypertensive patients $(n=194)$. The lengths of hospitalization and intensive care unit stay of these cases were longer than other cases by 9.6 and $8.9 \%$, respectively. At the same time, BMI values were significantly higher in these cases $(p=0.001)$. Hypertension was found to increase the AF incidence by 1.6 -fold $(p=0.011 ; \mathrm{OR}=1.59 \% 95 \mathrm{CI}=1.11-2.29)$, infection incidence by 1.4 -fold $(p=0.232$; OR $=1.43 \% 95 \mathrm{CI}=0.80$ 2.43 ), and mortality by 2 -fold $(\% 3.4 ; p=0.146 ; \mathrm{OR}=$ $2.01 \% 95 \mathrm{CI}=0.77-5.29)$.

When the factors affecting the duration of hospitalization were examined (Table 2), the POAF was found to be the major contributing factor by $34 \%$. The effect of such factors as BMI and WC on the length of hospital stay was $21-23 \%$ (Fig. 2). Cases with DM and MS were found to have longer duration of hospitalization by $18 \%$ (Figs. 2 and 3). Duration of hospitalization was significantly prolonged by infection $(23.2 \% ; p=0.001)$, stroke (24.5\%; $p=0.001)$, low LVEF (\%7; $p=0.035)$, and age (\%11.3; $p=0.002$; Figs. 2 and 3 ).

\section{Discussion}

Many studies, report 15-40\% AF incidence within 1-5 days after surgery [8]. Its clinical significance depends on the underlying factor. Within the first $2 \mathrm{~h}, 30 \%$ of POAF cases recover spontaneously. It has been reported that $25-80 \%$ of POAF cases recover in $24 \mathrm{~h}$ by using only the digoxin [9]. Mathew et al. reported that POAF was affected by older age, male gender, HT, AF history, heart failure, valvular disease, COPD, preoperative digoxin use, and non-use of beta-blockers preoperatively [10]. The incidence of POAF has been reported be more in cases whose surgery encompasses pulmonary vent placement and/or bicaval cannulation [10]. Since our series consisted of coronary artery bypass cases, bicaval cannulation and pulmonary venting were not performed. 
Table 2 The analysis of effect of preoperative demographic characteristics of patients on mortality, hospitalization, ICU stay, stroke, infection and bleeding. ( $A C E=$ angiotensin converting enzyme, $H T=$ hypertension, COPD = Chronic Obstructive Lung Disease) $\left(p^{b}=\right.$ Pearson Chi-square test, $p^{a}=$ Independent Sample t-test, $p^{c}=$ One Way Anova test)

\begin{tabular}{|c|c|c|c|c|c|c|c|c|c|c|c|c|c|c|c|c|c|c|c|}
\hline & & \multicolumn{2}{|c|}{ Mortality } & \multirow[t]{2}{*}{$p^{b}$} & \multicolumn{2}{|c|}{ Hospitalization } & \multirow[t]{2}{*}{$p^{a, c}$} & \multicolumn{2}{|c|}{ ICU Stay } & \multirow[t]{2}{*}{$p^{a, c}$} & \multicolumn{2}{|c|}{ Strok } & \multirow[t]{2}{*}{$p^{b}$} & \multicolumn{2}{|c|}{ Infection } & \multirow[t]{2}{*}{$p^{b}$} & \multicolumn{2}{|c|}{ Bleeding } & \multirow[t]{2}{*}{$p^{b}$} \\
\hline & & Not & Yes & & Ort. & Ss & & Ort. & Ss & & Not & Yes & & Not & Yes & & Not & Yes & \\
\hline \multirow[t]{2}{*}{ Gender } & Female & 225 & 4 & 0,54 & 8,2 & 1,94 & 0,41 & 1,9 & 1,8 & 0,66 & 217 & 12 & 0,52 & 209 & 20 & 0,47 & 223 & 6 & 0,42 \\
\hline & Male & 514 & 13 & & 8,1 & 1,71 & & 1,9 & 1,7 & & 505 & 22 & & 489 & 38 & & 507 & 20 & \\
\hline \multirow[t]{2}{*}{ ACE } & $(-)$ & 465 & 9 & 0,40 & 8,1 & 1,77 & 0,04 & 1,8 & 1,7 & 0,27 & 452 & 22 & 0,80 & 444 & 30 & 0,07 & 457 & 17 & 0,77 \\
\hline & $(+)$ & 274 & 8 & & 8,3 & 1,79 & & 2,0 & 1,8 & & 270 & 12 & & 254 & 28 & & 273 & 9 & \\
\hline \multirow[t]{2}{*}{ Statin Use } & $(-)$ & 667 & 17 & 0,35 & 8,1 & 1,76 & 0,15 & 1,9 & 1,8 & 0,44 & 651 & 33 & 0,18 & 633 & 51 & 0,49 & 661 & 23 & 0,73 \\
\hline & $(+)$ & 72 & 0 & & 8,4 & 1,94 & & 1,8 & 0,8 & & 71 & 1 & & 65 & 7 & & 69 & 3 & \\
\hline \multirow[t]{2}{*}{ Beta Blocker } & $(-)$ & 510 & 12 & 0,89 & 8,1 & 1,72 & 0,80 & 1,9 & 1,7 & 0,74 & 496 & 26 & 0,34 & 482 & 40 & 0,99 & 505 & 17 & 0,68 \\
\hline & $(+)$ & 229 & 5 & & 8,2 & 1,91 & & 1,9 & 1,7 & & 226 & 8 & & 216 & 18 & & 225 & 9 & \\
\hline \multirow[t]{2}{*}{ POAF } & $(-)$ & 581 & 14 & 0,71 & 8,0 & 1,72 & 0,01 & 1,9 & 1,7 & 0,24 & 584 & 11 & 0,01 & 553 & 42 & 0,24 & 573 & 22 & 0,45 \\
\hline & $(+)$ & 158 & 3 & & 8,9 & 1,82 & & 2,0 & 1,7 & & 138 & 23 & & 145 & 16 & & 157 & 4 & \\
\hline \multirow[t]{2}{*}{ Metabolic Syndrome } & $(-)$ & 519 & 10 & 0,31 & 8,0 & 1,64 & 0,01 & 1,8 & 1,5 & 0,02 & 510 & 19 & 0,07 & 496 & 33 & 0,02 & 509 & 20 & 0,43 \\
\hline & $(+)$ & 220 & 7 & & 8,6 & 2,02 & & 2,1 & 2,1 & & 212 & 15 & & 202 & 25 & & 221 & 6 & \\
\hline \multirow[t]{2}{*}{ HT } & $(-)$ & 513 & 9 & 0,15 & 8,0 & 1,70 & 0,01 & 1,8 & 1,6 & 0,01 & 501 & 21 & 0,35 & 486 & 36 & 0,23 & 502 & 20 & 0,38 \\
\hline & $(+)$ & 226 & 8 & & 8,4 & 1,94 & & 2,1 & 2,0 & & 221 & 13 & & 212 & 22 & & 228 & 6 & \\
\hline \multirow[t]{2}{*}{ Diabetes Mellitus } & $(-)$ & 479 & 10 & 0,61 & 8,0 & 1,63 & 0,01 & 1,8 & 1,5 & 0,01 & 472 & 17 & 0,07 & 458 & 31 & 0,06 & 473 & 16 & 0,73 \\
\hline & $(+)$ & 260 & 7 & & 8,5 & 1,98 & & 2,1 & 2,0 & & 250 & 17 & & 240 & 27 & & 257 & 10 & \\
\hline \multirow[t]{3}{*}{ BMI } & $<25$ & 283 & 5 & 0,39 & 7,8 & 1,46 & $0,01^{c}$ & 1,8 & 1,6 & $0,06^{\mathrm{c}}$ & 278 & 10 & 0,27 & 282 & 6 & 0,01 & 281 & 7 & 0,49 \\
\hline & $25-30$ & 262 & 5 & & 8,2 & 1,78 & & 1,8 & 1,6 & & 256 & 11 & & 242 & 25 & & 256 & 11 & \\
\hline & $>30$ & 194 & 7 & & 8,7 & 2,06 & & 2,1 & 2,0 & & 188 & 13 & & 174 & 27 & & 193 & 8 & \\
\hline \multirow[t]{2}{*}{ Cigaret Use } & $(-)$ & 502 & 11 & 0,78 & 8,3 & 1,95 & 0,01 & 2,0 & 1,9 & 0,01 & 487 & 26 & 0,27 & 470 & 43 & 0,29 & 492 & 21 & 0,15 \\
\hline & $(+)$ & 237 & 6 & & 7,9 & 1,35 & & 1,7 & 1,3 & & 235 & 8 & & 228 & 15 & & 238 & 5 & \\
\hline \multirow[t]{2}{*}{ COPD } & $(-)$ & 527 & 15 & 0,13 & 8,3 & 1,93 & 0,01 & 2,0 & 1,9 & 0,01 & 514 & 28 & 0,16 & 496 & 46 & 0,18 & 522 & 20 & 0,55 \\
\hline & $(+)$ & 212 & 2 & & 7,9 & 1,29 & & 1,6 & 1,1 & & 208 & 6 & & 202 & 12 & & 208 & 6 & \\
\hline \multirow[t]{3}{*}{ Age } & $18-35$ & 32 & 2 & 0,20 & 8,0 & 2,24 & $0,12^{c}$ & 2,1 & 1,8 & $0,52^{c}$ & 33 & 1 & 0,07 & 32 & 2 & 0,03 & 31 & 3 & 0,02 \\
\hline & $35-55$ & 280 & 8 & & 8,0 & 1,67 & & 1,8 & 1,6 & & 281 & 7 & & 275 & 13 & & 277 & 11 & \\
\hline & $56-78$ & 427 & 7 & & 8,3 & 1,81 & & 1,9 & 1,8 & & 408 & 26 & & 391 & 43 & & 422 & 12 & \\
\hline Waist circumference ( & nean/cm) & Mear & & $p^{a}$ & & & & & & & Mear & & $p^{a}$ & Mear & & $p^{a}$ & Mean & & $p^{a}$ \\
\hline & & 83 & 88 & 0,20 & & & & & & & 83 & 91 & 0,01 & 83 & 90 & 0,01 & 83 & 86 & 0,40 \\
\hline
\end{tabular}

$88 \%$ of the POAF cases developed within postoperative 1-5th days and $98 \%$ of these recovered within 1-3 days. As the LVEF value decreased, the incidence of POAF increased but the relationship was not significant (Figs. 3 and 4). Significant results may be obtained, however, in the series in which very low LVEF cases are included. In our cases, it was found that DM, MS, obesity, and advanced age had affected POAF positively. On the other hand, significant negative correlation (6.9\%) between POAF and beta-blocker use was detected (Table 1; Fig. 2) . However, statin and ACE inhibitor use were not found to be correlated with POAF $(p>0.05)$. Mathew et al. [10] have found an association between ACE inhibitor or statin use and POAF, which can be explained by the fact that the number of cases using these drugs was higher than our count. It was found that POAF significantly increased the length of hospitalization and ICU stay, and the stroke rate (Figs. 3, 4 and 6).

Roffman et al. reported that as the number of bypass grafts or the CPB duration increases, the rate of arrhythmia increases [11]. As Bannister et al. reported, the increase in CPB duration deranges the mechanism by which glucose is transported into the cell and thus blood glucose level is elevated. As a result, metabolic acidosis occurs. When the patient is warming up, the insulin response increases but hyperglycemia persists for another 1-2 $\mathrm{h}$. In addition, the metabolism of thyroid hormones is affected and the level of triiodothyronine $\left(\mathrm{T}_{3}\right)$ falls [12]. In our study, there was no difference between the number of bypasses, and total and partial $\mathrm{CPB}$ 


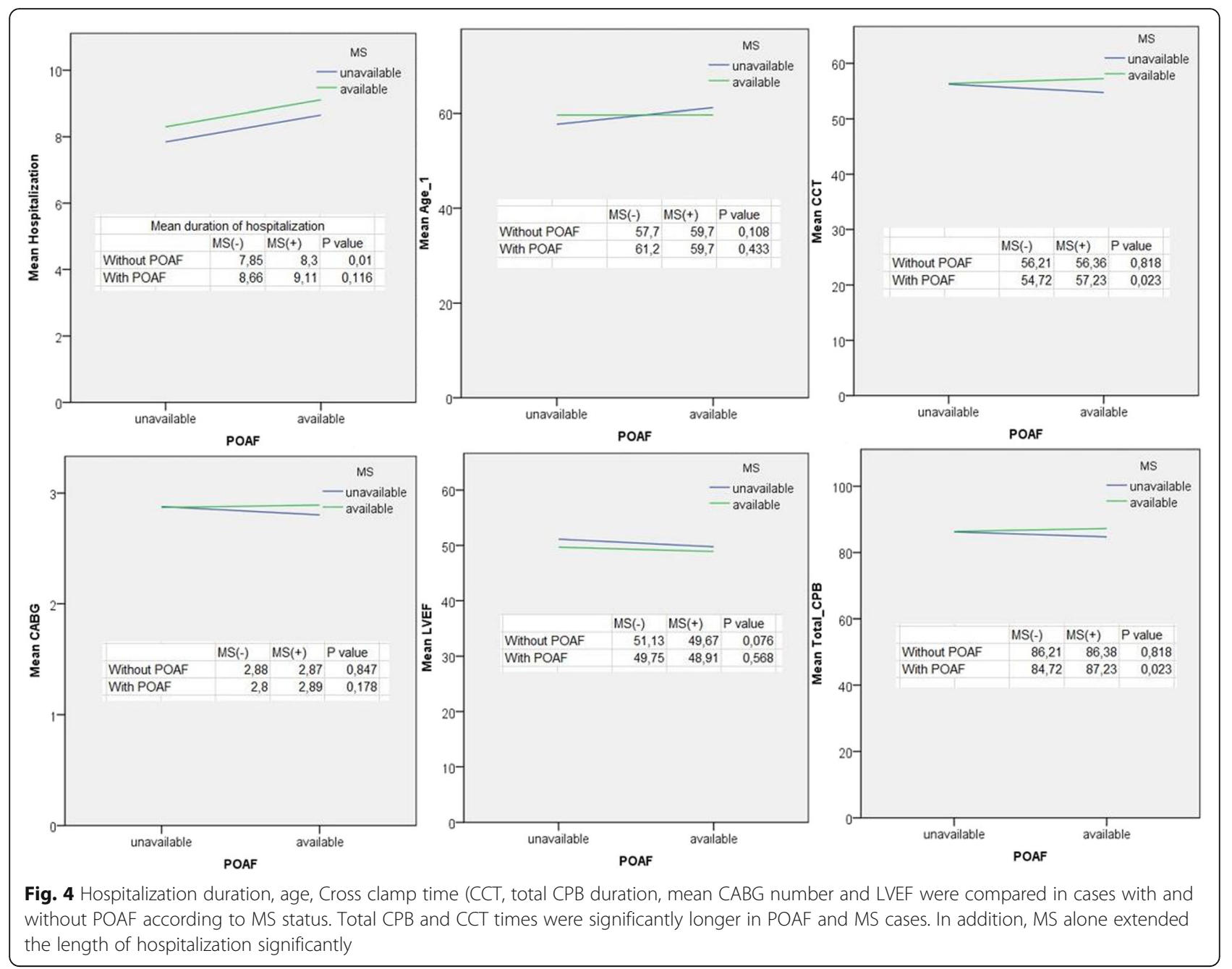

durations of the cases (Table 1, Fig. 4). If studies with groups with different total and partial CPB durations are performed, it could be analyzed whether this difference is a factor affecting POAF or not.

Studies have reported 34\% prevalence of abdominal obesity in the population of 20 years of age and over in Turkey [13]. Although abdominal obesity is an important indicator of insulin resistance, obesity may not be present in some of the metabolic syndrome cases with insulin resistance. As the BMI increases, there is a gradual increase in left atrial dimensions. Ducceschi et al. reported that they found higher frequency of AF and left atrial dilatation in a series of 150 cases with BMI $\geq 30 \mathrm{~kg} /$ $\mathrm{m}^{2}$ [14]. In atrial biopsies of patients with atrial fibrillation, inflammatory mediators were detected high. This may explain the development of AF from postoperative inflammation [15]. It is believed that abdominal obesity increases the level of inflammatory cells and facilitates the development of AF with the released mediators. Adipose tissue is an active endocrine organ that secretes many hormones like leptin, resistin, adiponectin, and cytokines (TNF-alpha, IL-6, IL-8). Released cytokines cause systemic inflammation and affect insulin resistance and pulmonary functions [16]. In our study, we found that both high BMI measurements and high WC scores affected POAF significantly $(p=0.001)$. The mean $\mathrm{WC}$ value was $90.1 \pm 12.6 \mathrm{~cm}$ in the POAF developed cases while it was $81.6 \pm 14 \mathrm{~cm}$ in the cases that had not developed POAF (Table 2). Although WC values were higher in cases with postoperative complications such as mortality, infection, bleeding and stroke, it was found to be significant only in cases developing stroke and infection (Table 2).

The body mass index is an indicator of total fat accumulation and does not represent the distribution of fat or metabolic distress. It has also been reported in previous studies that obesity is defined by BMI and is an independent risk factor for POAF [17]. There have been recent reports that conclude obesity has no effect on POAF [17]. Differences between studies may be related to the heterogeneous distribution of fat and the rate of accumulation of cardiotoxic metabolites. In parallel with most centers, our opinion is that WC measurement is more reliable than 


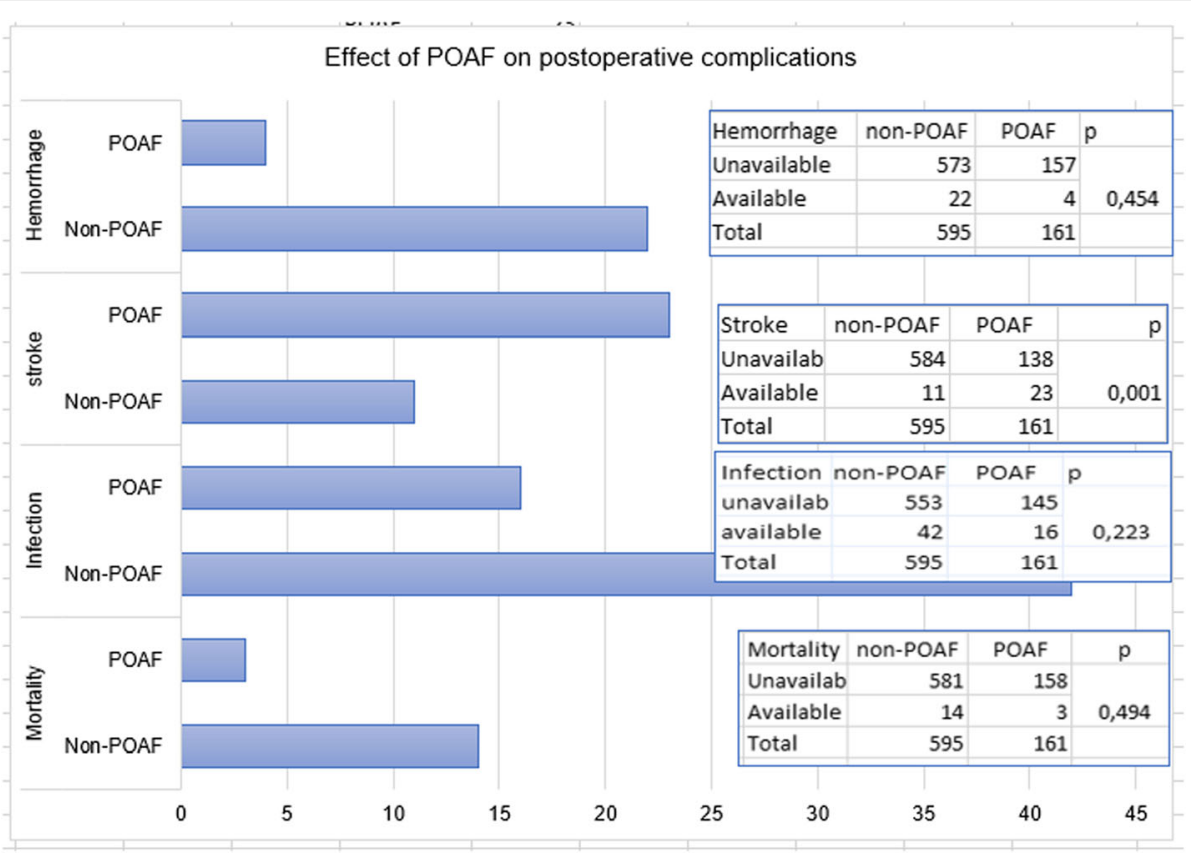

Fig. 5 Graphical analysis of the effect of POAF on postoperative complications. POAF affected only the stroke rate significantly

BMI as a diagnostic parameter for MS. In our study, we found that the incidence of POAF was affected by obesity by 1.65 -fold while by MS by 2.46 -fold (Fig. 2).

In MS, endothelial dysfunction has been reported to develop before clinical symptoms occur [18]. This may contribute to the view that endothelial dysfunction plays a role in the development of POAF in MS. Almassi et al. reported 2 -fold higher hospital mortality (3\% versus $6 \%$ ) in post-operative AF cases [19]. The 6-month mortality rate was reported to be $4.7 \%$ vs $9 \%$. We think that this

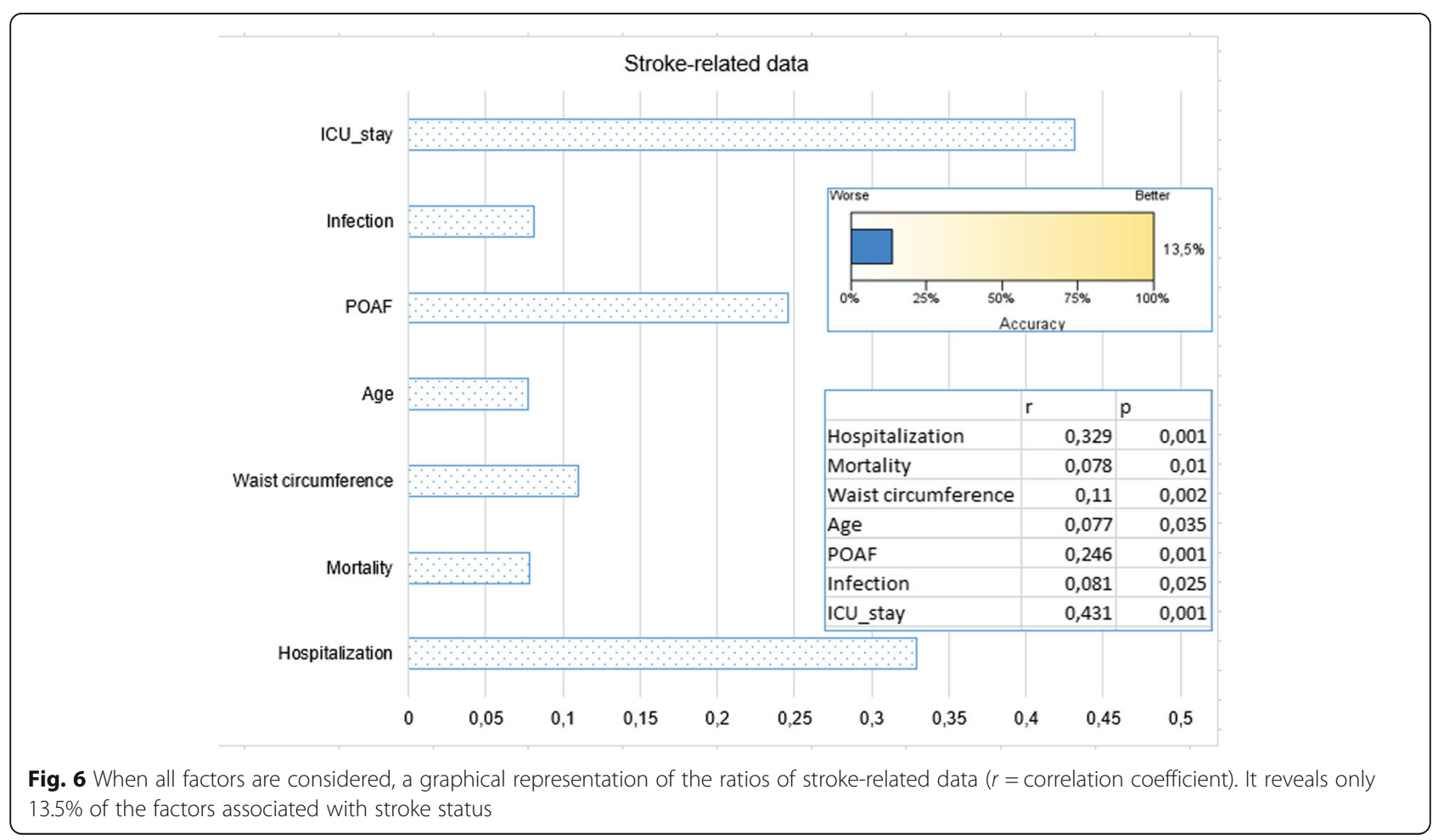


mortality difference is due to the factors that paved the way for POAF development in addition to POAF. Since the duration of follow up in our study was limited to the length of hospitalization, it was not possible to determine the mid and long-term mortality. However, hospital mortality was not significantly different between POAF and Non-POAF cases (2.2\%). Mortality of cases diagnosed with MS was found to be increased by 2.4 times (Figs. 1 and 5) with POAF, whereas by 1.7 times without POAF. As it is understood from these results, it would be incomplete to think that only POAF increases mortality. POAF also increases postoperative morbidity. In cases with MS, POAF was found to increase the length of the hospitalization by $31 \%(p=0.001)$. In our study, we found that MS increased the infection and stroke incidence by 1.9-fold while the stroke was more frequent in patients in MS cases who developed POAF (Figs. 2, 3 and 6).

Geographical region and race were found to be effective in the development of POAF as following regional incidences indicate: Middle East (41.6\%), USA (33.7\%), Europe (34\%), Canada (36.6\%), South America (17.4\%), Asia (15.7\%) [20]. This differentiation may be related to the incidence of MS as well as indicating that the white race is more prone to POAF. However, there is a need for meta-analyzes of large series and cohort studies in which the accompanying factors are examined. In our cases, the incidence of POAF is $21.3 \%$, similar to the geographical distribution, though the $32.6 \%$ incidence rate of POAF in MS cases s differentiated from the literature data. In addition, the prevalence rate of MS in our series $(30 \%)$ was similar to the prevalence of MS in the literature (33\%) [2].

The incidence of AF in the general population (0.4$1 \%)$ has been reported to increase by age such that it is $8 \%$ over the age of 80 [21]. In elderly patients, the increase in the rate of POAF is also due to changes in the cardiac fibrosis and atrial dilation [22]. In our series, in the cases without MS, the rate of AF which was $25 \%$ in the $18-35$ age group increased to $27.4 \%$ in the $56-78$ age group. However, in cases where metabolic syndrome was added, these rates increased up to 50\% (Table 1). The rate of postoperative infection in the same age group was $9.9 \%(p=0.026)$. Effect of the age on the length of hospitalization in the POAF developed cases was found to be $10.7 \%(p=0.012)$ and that was statistically significant (Table 1 ). We think that besides the degree of atrial fibrosis increasing with age, MS which is more common in older ages is also effective on the increase of POAF incidence. In addition to such preventable causes as surgical dissection, manipulation, pericardial injury, pericarditis, left ventricular dysfunction and atrial dilation due to intraoperative volume overload, electrolyte irregularities, and blood transfusion, techniques for administering the cardioplegia and inadequate atrial cooling could activate the complement system through oxidative stress-induced release of inflammatory mediators [23]. Supporters of this theory argue that the use of antiinflammatory drugs together with corticosteroids and statins reduces the rate of POAF [10, 24]. Since all our cases had similar temperatures and durations of $\mathrm{CPB}$, we believe that the effect of such confounding factors on the results was not significant.

It has been reported that $60 \%$ of postoperative $\mathrm{AF}$ cases have HT [24]. Patti et al., report that HT is an independent risk factor for POAF [25]. In our study, the AF rate (27\%) in the cases with HT was found to be significant. Hospital mortality in those with HT was twice as high. Blood pressure control can be an important strategy in preventing AF.

We observed that the incidence of stroke was 8,85 times as high (Figs. 2, 3 and 6) in patients with atrial fibrillation. Our treatment strategy was to restore hemodynamic stability, prevent thromboembolism, and eliminate metabolic problems. The choice of anticoagulant treatment for sustaining AF cases was done according to the CHA2DS2VASC scoring system. Guidelines issued by the ESC in 2010 recommended the use of the CHA2DS2VASC scoring system [26]. By utilizing this scoring system created with large series, the expected risk of thromboembolism is calculated, and the appropriate anticoagulant treatment is determined.

\section{Limitations of the study}

In our study, in cases with obesity and MS, left atrial diameter, a determinant of POAF, was not measured. Left atrial dilation, though an independent risk factor, may be responsible for some of the effects of MS or obesity on POAF. This can be determined by detailed echocardiographic examination. However, we believe that the interaction is not much since our cases did not have valve problems and the COPD patient count was low.

In the analysis of the effect of clinical factors on the POAF in the 18-35 age group, the absence of association may be due to the low number of samples in the group. In this group, the low number of cases was since atherosclerosis was rarely seen in this age group and PTCA method (stenting) was preferred in the treatment. However, this number, which we could still reach, was insufficient when divided into groups, but as a single group, it was enough for analysis. Patients with MS and obesity were hospitalized longer. This may lead to a prejudice that the capture rate of the POAF could have been affected.

\section{Conclusion}

In our study, it was observed that POAF was common in obesity, MS, HT, DM and elderly patients and that it significantly prolonged hospital stay. Although AF incidence was lower in patients using beta blocker, it was 
not significant. In POAF cases, stroke rate was 8,85 times higher. POAF was found to be positively correlated with WC and BMI measurements. Obesity was found to be one of the important risk factors for POAF independent of MS.

Metabolic syndrome and obesity are important factors that decrease the quality of life by increasing the incidence of POAF after coronary bypass surgery. If the causes and mechanisms of POAF are determined, we believe that by reducing the factors leading to atrial fibrillation, hospital cost and morbidity will be reduced, in planned cardiovascular interventions.

\section{Abbreviations}

ACE: Angiotensin converting enzyme inhibitor; AF: Atrial fibrillation; BMl: Body mass index; CABG: Coronary artery bypass grafting; CCT: Cross clamp time; COPD: Chronic obstructive pulmonary disease;

CPB: Cardiopulmonary bypass; DM: Diabetes mellitus;

ECG: Electrocardiography; HDL: High-density lipoprotein; HT: Hypertension; IABP: Intraaortic balloon pump; ICU: Intensive care unit; LVEF: Left ventricular ejection fraction; MI: Myocardial infarction; MS: Metabolic syndrome; POAF: Postoperative atrial fibrillation; TG: Triglyceride; WC: Waist circumference

\section{Acknowledgements}

We shall like to thank the Dr. Siyami Ersek Thoracic and Cardiovascular Surgery Center for allowing and facilitating us to conduct this study. We also like to acknowledge all the participants for their time and cooperation. We shall like to thank Prof. Dr. Ibrahim Yekeler and Dr. Ferruh Elbir for providing the logistic support during data collection.

\section{Authors' contributions}

UV was responsible for the conception and design of the study. AAA provided the technical suggestions and support in conducting the experiments. UV wrote the first draft and added important intellectual content. UV and AAA contributed to the data collection and analysis. UV and AAA contributed to refining the ideas and edited the manuscript. All authors contribute to critical revisions and agree to be accountable for all aspects of the work. Both authors read and approved the final manuscript.

\section{Funding}

No financial support was received for this submission.

\section{Availability of data and materials}

The datasets used and analyzed during the current study are available from the corresponding author on reasonable request.

\section{Ethics approval and consent to participate}

This study was performed at Dr. Siyami Ersek Thoracic and Cardiovascular Surgery Center Istanbul, Turkey. The study protocol was approved by the Health Sciences University Siyami Ersek Cardiovascular Surgery Hospital Ethics Committee decision dated 16/06/2015 and numbered (Number No: 28001928-501.07.01) and the patients were informed in writing. Informed consent was waived by Institutional Review Board owing to the study's retrospective nature. Following the approval of the ethics committee, permission for access to raw data was provided by the data processing center with the permission of Chief Physician of The Dr. Siyami Ersek Thoracic and Cardiovascular Surgery. The methodology of the study was designed based on the tenets of the Helsinki Declaration.

\section{Consent for publication}

Not applicable.

\section{Competing interests}

The authors declare that they have no competing interests.
Received: 2 November 2018 Accepted: 11 June 2019

Published online: 17 June 2019

\section{References}

1. Ford ES, Giles WH, Mokdad AH. Increasing prevalence of the metabolic syndrome among u.s. adults. Diabetes Care. 2004;27(10):2444-9.

2. Kozan O, Oguz A, Abaci A, Erol C, Ongen Z, Temizhan A, Celik S. Prevalence of the metabolic syndrome among Turkish adults. Eur J Clin Nutr. 2007;61(4):548-53.

3. Jidéus $L$, Blomström $P$, Nilsson $L$, Stridsberg M, Hansell $P$, BlomströmLundqvist C. Tachyarrhythmias and triggering factors for atrial fibrillation after coronary artery bypass operations. Ann Thorac Surg. 2000;69(4):1064-9.

4. Barrett TW, Storrow AB, Jenkins CA, Harrell FE Jr, Miller KF, Moser KM, Russ S, Roden DM, Darbar D. Atrial fibrillation and flutter outcomes and risk determination (AFFORD): design and rationale. J Cardiol. 2011;58(2):124-30.

5. Delaney JA, Yin X, Fontes JD, Wallace ER, Skinner A, Wang N, Hammill BG, Benjamin EJ, Curtis LH, Heckbert SR. Hospital and clinical care costs associated with atrial fibrillation for Medicare beneficiaries in the cardiovascular health study and the Framingham heart study. SAGE Open Med. 2018;6:2050312118759444.

6. Watanabe H, Tanabe N, Watanabe T, Darbar D, Roden DM, Sasaki S, Aizawa Y. Metabolic syndrome and risk of development of atrial fibrillation: the Niigata preventive medicine study. Circulation. 2008;117(10):1255-60.

7. Arslan M, Atmaca A, Ayvaz A, Başkal N, Beyhan Z, Bolu E, Can S, Çorakçı A, Dağdelen S, Demirağ NG, Demirer AN, Erbaş T, Gürsoy A, Güllü S, Ilgın ŞD, Karakoç A, Kulaksızoğlu M, Şahin M, Tanacı N, Törüner F, Tütüncü NB, Üçkaya G, Yetkin I, Yılmaz M. Metabolic syndrome guide Turkey endocrinology and metabolism association. 1st ed. Ankara: Tuna Printing Industry and Trade Inc; 2009. p. 8. Available from: http://temd.org.tr/admin/ uploads/tbl_publications/metabolic_sendrom.pdf.

8. Ferreira AF, A Saraiva F, Moreira R, J Cerqueira R, J Amorim M, Pinho P, P Lourenço A, F Leite-Moreira A. Postoperative atrial fibrillation after coronary artery bypass grafting surgery. Rev Port Cir Cardiothorac Vasc. 2017;24(3-4): 129 PMID: 29701361

9. Cochrane $A D$, Siddins M, Rosenfeldt FL, Salamonsen R, McConaghy L, Marasco S, Davis BB. A comparison of amiodarone and digoxin for treatment of supraventricular arrhythmias after cardiac surgery. Eur J Cardiothorac Surg. 1994:8(4):194-8.

10. Mathew JP, Parks R, Savino JS, Friedman AS, Koch C, Mangano DT, Browner WS. Atrial fibrillation following coronary artery bypass graft surgery: predictors, outcomes, and resource utilization. Multicenter study of perioperative ischemia research group. JAMA. 1996;276(4):300-6.

11. Roffman JA, Fieldman A. Digoxin and propranolol in the prophylaxis of supraventricular tachydysrhythmias after coronary artery bypass surgery. Ann Thorac Surg. 1981;31(6):496-501.

12. Bannister CF, Finlayson DC. The endocrine system: effects of cardiopulmonary bypass. In: Mora CT, Guyton RA, Finlayson DC, Rigatti RL, editors. Cardiopulmonary bypass 1995:180-195. New York: Springer. Online ISBN: 978-1-4612-2484-6.

13. Satman I, Yilmaz T, Sengül A, Salman S, Salman F, Uygur S, Bastar I, Tütüncü Y, Sargin M, Dinççag N, Karsidag K, Kalaça S, Ozcan C, King H. Population-based study of diabetes and risk characteristics in Turkey: results of the Turkish diabetes epidemiology study (TURDEP). Diabetes Care. 2002;25(9):1551-6.

14. Ducceschi V, D'Andrea A, Liccardo B, Alfieri A, Sarubbi B, De Feo M, Santangelo L, Cotrufo M. Perioperative clinical predictors of atrial fibrillation occurrence following coronary artery surgery. Eur J Cardiothorac Surg. 1999;16(4):435-9.

15. Ucar HI, Tok M, Atalar E, Dogan OF, Oc M, Farsak B, Guvener M, Yilmaz M, Dogan R, Demircin M, Pasaoglu I. Predictive significance of plasma levels of interleukin- 6 and high-sensitivity C-reactive protein in atrial fibrillation after coronary artery bypass surgery. Heart Surg Forum. 2007;10(2):131-5.

16. Aizawa K, Shoemaker JK, Overend TJ, Petrella RJ. Metabolic syndrome, endothelial function and lifestyle modification. Diab Vasc Dis Res. 2009:6(3):181-9.

17. Wanahita N, Messerli FH, Bangalore S, Gami AS, Somers VK, Steinberg JS. Atrial fibrillation and obesity-results of a meta-analysis. Am Heart J. 2008:155(2):310-5.

18. Berberoğlu Z, Demirağ G. Metabolic syndrome: endothelial dysfunction, subclinical inflammation and hypercoagulability. Turkish Clinics J Int Med Sci. 2006;2(3):60-70. Available from: http://www.turkiyeklinikleri.com/article/ en-metabolik-sendrom-endotel-disfonksiyonu-subklinik-inflamasyon-vehiperkoagulabilite-44663.html. 
19. Almassi GH, Schowalter T, Nicolosi AC, Aggarwal A, Moritz TE, Henderson WG Tarazi R, Shroyer AL, Sethi GK, Grover FL, Hammermeister KE. Atrial fibrillation after cardiac surgery: a major morbid event? Ann Surg. 1997;226(4):501-11.

20. Nazeri A, Razavi M, Elayda MA, Lee W, Massumi A, Wilson JM. Race/ethnicity and the incidence of new-onset atrial fibrillation after isolated coronary artery bypass surgery. Heart Rhythm. 2010;7(10):1458-63.

21. Flegel KM, Shipley MJ, Rose G. Risk of stroke in nonrheumatic atrial fibrillation. Lancet. 1987;1 (8532):526-9.

22. Kotfis K, Szylińska A, Listewnik M, Strzelbicka M, Brykczyński M, Rotter I, Żukowski M. Early delirium after cardiac surgery: an analysis of incidence and risk factors in elderly ( $\geq 65$ years) and very elderly ( $\geq 80$ years) patients. Clin Interv Aging. 2018;13:1061-70.

23. Liu S, Li Z, Liu Z, Hu Z, Zheng G. Blood transfusion and risk of atrial fibrillation after coronary artery bypass graft surgery: A meta-analysis of cohort studies. Medicine (Baltimore). 2018;97(10):e9700.

24. Bell DSH, O'Keefe JH. Metabolic syndrome and postoperative atrial fibrillation (POAF). Eur Heart J. 2009:30(10):1167-8.

25. Patti G, Chello M, Candura D, Pasceri V, D'Ambrosio A, Covino E, Di Sciascio $G$. Randomized trial of atorvastatin for reduction of postoperative atrial fibrillation in patients undergoing cardiac surgery: results of the ARMYDA-3 (atorvastatin for reduction of myocardial dysrhythmia after cardiac surgery) study. Circulation. 2006;114(14):1455-61.

26. European Heart Rhythm Association, European Association for CardioThoracic Surgery, Camm AJ, Kirchhof P, Lip GY, Schotten U, Savelieva I, Ernst S, Van Gelder IC, Al-Attar N, Hindricks G, Prendergast B, Heidbuchel H, Alfieri O, Angelini A, Atar D, Colonna P, De Caterina R, De Sutter J, Goette A, Gorenek B, Heldal M, Hohloser SH, Kolh P, Le Heuzey JY, Ponikowski P Rutten FH. Guidelines for the management of atrial fibrillation the task force for the management of atrial fibrillation of the European Society of Cardiology (ESC). Eur Heart J. 2010;31(19):2369-429.

\section{Publisher's Note}

Springer Nature remains neutral with regard to jurisdictional claims in published maps and institutional affiliations.

Ready to submit your research? Choose BMC and benefit from:

- fast, convenient online submission

- thorough peer review by experienced researchers in your field

- rapid publication on acceptance

- support for research data, including large and complex data types

- gold Open Access which fosters wider collaboration and increased citations

- maximum visibility for your research: over $100 \mathrm{M}$ website views per year

At $\mathrm{BMC}$, research is always in progress.

Learn more biomedcentral.com/submissions 